\title{
Dietary Patterns and Nutritional Status of Patients with Early Stages Liver
}

\section{Cirrhosis}

\author{
Azza Saad Husseiney Mandoor, Nursing Teacher \\ The Secondary Technical Nursing School, Kafr El-Sheikh
}

Haneya Abd El.Hameed El.Banna, Professor

Medical Surgical Nursing, Faculty of Nursing, Alexandria University

Mervat Abdel Fattah Mohamed, Assistant Professor

Medical Surgical Nursing, Faculty of Nursing, Alexandria University

Fayza Mohammed Tawfik, Assistant Professor

Medical Surgical Nursing, Faculty of Nursing, Alexandria University

\begin{abstract}
Liver cirrhosis is a condition in which the liver does not function properly due to long-term damage. Early nutritional assessment and intervention are imperative to prevent further catabolism and malnutrition in liver cirrhosis. Moreover, dietary patterns mean the quantities, proportions, variety or combinations of different foods and beverages in diets, and the frequency with which they are habitually consumed. And nutritional status is the condition of health of a person that is influenced by the intake and utilization of nutrients. Objective: Assess dietary patterns and nutritional status of patients with early stages liver cirrhosis. Setting: The study was conducted at Medical outpatients clinic at Saidy Salim General Hospital affiliated to Ministry of Health and Population at Kafr ElSheikh Governorate. Subjects: 254 adult patients diagnosed early stage liver cirrhosis were involved in this study. Tool: One tool was used for data collection; early stage liver cirrhosis patients dietary patterns and nutritional status structured interview schedule. Results: More than two thirds of studied patients $(73.6 \%)$ were $\geq 50$ years. And more than half of them (59.1\%) were females. Also, no severe symptoms were experienced among the study patients, and the majority of them (78.6\%) were having mild symptoms, and about (41.3\%) were having moderate symptoms. Moreover, no significant correlations were elicited between overall dietary patterns and patients nutritional status. Conclusion: High prevalence of malnutrition in early stages cirrhotic patients together with the lack of simple and accurate methods of assessment of malnutrition among these patients' population, it is reasonable to assume that malnutrition occurs in all patients. Recommendations: Regular and complete nutritional assessment of liver cirrhosis patients should be carried out for early detection and treatment of malnutrition. Nutritional health education program must be organized for early stages liver cirrhotic patients in order to limit the occurrence of further malnutrition and its complications.
\end{abstract}

Keywords: Early stages liver cirrhosis; Dietary patterns; Nutritional status.

\section{Introduction}

Liver cirrhosis is a condition in which the liver does not function properly due to long-term damage. This damage is characterized by the replacement of normal liver tissue by scar tissue. Typically, the disease develops slowly over months or years. In early stages, there are often no symptoms $^{(1)}$.
Common causes of cirrhosis include long-term alcohol abuse, hepatitis B and C infection, and fatty liver disease. According to the World Health Organization (WHO), hepatitis $\mathrm{B}$ and $\mathrm{C}$ together are the most leading causes of cirrhosis ${ }^{(2,3)}$. Regarding, early symptoms of liver failure are fairly general, making it difficult to know that the liver is failing. Moreover, in early stages inflammation is occur but there are no symptoms including bleeding in the 
digestive tract, jaundice, mental effects, edema and intense, unexplained skin itching $^{(4)}$.

Symptoms of liver cirrhosis may include nausea, appetite changes, fatigue, diarrhea, jaundice, easy bleeding. As the condition worsens, symptoms might include mental confusion and coma ${ }^{(5,6,7)}$.

Liver cirrhosis patients often suffer from malnutrition due to decrease in nutrient consumption or impaired liver metabolism. Also, patients with malnutrition have been recognized to have greater risk for increased complications and mortality ${ }^{(8)}$. Krenitski (2003) stated that malnutrition is prevalent in all forms of liver diseases ${ }^{(9)}$.

The American Society for Parenteral and Enteral Nutrition (A.S.P.E.N.) (2012) defined nutritional assessment as a comprehensive approach to define nutrition status that uses medical, nutrition and social histories, physical examination, anthropometric measurements and laboratory data ${ }^{(10)}$.

According to Previous (DGAC) examining specific foods, nutrients, and dietary components and their relationships to health outcomes, patients with cirrhosis do not have substantially greater total calorie requirements than other populations. So, healthy diet is a pillar of well-being throughout the lifespan. In addition, it promotes the achievement of healthy pregnancy outcomes; supports normal growth, development and aging; helps maintain healthful body weight; reduces chronic disease risks; and promotes overall health and well-being ${ }^{(11-13)}$.

In light of the high incidence of malnutrition among patients with liver cirrhosis and the complications that result from malnutrition in these patients, it is essential to assess the nutritional status of those patients in order to educate them the basics of nutritional therapy and initiate treatment for positive progression.

So, nurses play an important role in the multidisciplinary team to perform a comprehensive and continuous patient care $^{(14)}$. For, early nutritional assessment and intervention to prevent further catabolism and malnutrition in liver cirrhosis. In addition, early intervention by an educated nutritional provider and good patient compliance with recommendations can improve quality of life for patients and help to decrease development of morbidities related to malnutrition.

\section{Aim of the Study}

Assess dietary patterns and nutritional status of patients with early stages liver cirrhosis.

\section{$\underline{\text { Research Questions: }}$}

What are the dietary patterns and nutritional status of patients with early stages liver cirrhosis?

\section{Operational definition:}

Dietary patterns: are the quantities, proportions, variety or combinations of different foods and beverages in diets, and the frequency with which they are habitually consumed.

\section{Materials and Method}

\section{Materials}

Design: It was descriptive research design.

Setting: This study was conducted at the Medical Outpatients Clinic at Saidy Salim General Hospital. The hospital is affiliated to The Ministry of Health and the Population at Kafr El-Sheikh Governorate.

Subjects: A convenient sample of 254 adult patients having early stage liver cirrhosis constituted the sample of the study and showing up at the above mentioned setting. They were selected according to the following criteria:

- Free from other chronic and metabolic diseases as diabetes mellitus, cardiac or renal disease. 
- Free from associating complications (edema, ascites, encephalopathy) and not receiving antidiuretics as Lasix.

- Immediately on admission.

- Having liver cirrhosis (liver inflammation, with slight deterioration in liver functions) for not less than 6 months.

- Age group (21-60) years.

- Able and willing to participate.

Tool: One tool was used for data collection. It was entitled as:

Tool I: Early stages liver cirrhosis patients dietary patterns and nutritional status structured interview schedule ${ }^{(15-21)}$

The developed tool comprised three parts:

Part 1: This part comprised the following:

A. Socio-demographic data: these data included age, sex, area of residence, marital status, level of education, occupation, income, room number, number of family members (living at home), level of physical activity and having meals outside home:

- Etiology or underlying cause of the disease (long-term alcohol abuse, hepatitis $\mathrm{B}$ and $\mathrm{C}$ infections and fatty liver disease).

- Past medical history: this section included patients diagnosis, duration of the disease, medications for other diseases and on counter drugs e.g. laxatives or analgesics, vitamins, minerals and herbal preparations or others.

- Present medical history including patient's diagnosis, duration of the disease, current medications and oncounter drugs e.g. laxatives or analgesics, vitamins, minerals and herbal preparations or others.

- Patient's complaints included abdominal pain, nausea or others.
- Diagnostic procedures included: endoscopy, CT scan, x-ray or others.

- Medications increasing the need for diet included: anti-cholesterol, antibiotics, antihypertensive drugs, softeners and others.

- Medications causing indigestion included: anti-cholesterol, antibiotics, antihypertensive drugs, softeners and others.

Part 2: Dietary patterns: These patterns were assessed throughout:

A. 72-hour recall containing a list of food and drinks intake of the participants during the previous three days before admission with a full description of the usual serving size.

B. List of food consumption: this section is a list of food that the patients consumed and how often they were consumed.

List items were scored in a 6- point Likert scale where $1=$ more than one time daily, $2=$ one time daily, $3=2-3$ times per week, $4=$ once weekly, $5=$ rarely, $6=$ unpleasantly or not eaten:

Part 3: Used to assess nutritional status: It consisted of three main sections:

A. Clinical examination: This examination was carried out to assess subjective and objective physical signs of malnutrition as regard to:

1. General signs as: Tiredness', fever, chills, night sweats, daytime sleepiness, edema and/or abnormal swelling.

2. Alimentary signs as abdominal pain, nausea, vomiting, food intolerance and preferences, pain in swallowing and sore tongue.

3. Neurologic signs as Confusion or memory loss, gait disturbance, numbness and weakness. 
B. Anthropometrics measurements: These measurements included:

1. Height in $(\mathrm{cm})$.

2. Weight in $(\mathrm{kg})$.

3. Body Mass Index $(\mathrm{BMI})=$ Weight $(\mathrm{kg}) /$ height $(\mathrm{m} 2)$.

$-18.5-24.9=$ normal nutrition.

- 17.0 - 18.4=mild malnutrition.

- $16.0-16.9=$ moderate malnutrition.

- $<16.0=$ severe malnutrition.

4. Triceps skinfold thickness (TST): This measurement estimated by using digital calipers.

5. Mid-arm circumference (MAC): This measurement estimated by using measuring tapes:

Normal values are: $18.5-25.5 \mathrm{~cm}$ for adults.

6. Mid-arm muscle or arm muscle circumference

(MAMC):

Determined from:

Mid-arm circumference (MAC) and Triceps skin fold thickness (TST.

$\mathrm{Or}$

MAMC $(\mathrm{cm})=$ mid-arm circumference $-(0.314 \times$ TST [mm])

7. Body composition: Measure a lean body mass (including bone, muscle, water and fat percent) by using Body Fat/Hydration Monitor Scale (EXACTA). that work through entering height, age and sex of every patient alone through its touch screen and then the patient is asked to stand without shoes on it and the scale start automatically start to measure the patient's body composition components.

\section{C. "Biochemical measurements": This section included the following:}

1. Hemoglobin. 13-17 g/dL (men), $12-15 \mathrm{~g} / \mathrm{dL}$ (women)

2. White blood cells: $4-10 \times 10^{\wedge} 9 / \mathrm{L}$

3. Platelet count:150-400 x $10^{\wedge} 9 / \mathrm{L}$

4. Total lymphocyte count:1-4 $\mathrm{x}$ $10^{\wedge} 9 / \mathrm{L}$

5. Serum albumin:35-50 g/L

6. Prothrombine time: $11-14 \mathrm{sec}$

7. Prothrombine activity

\section{Method}

1. Written approvals to carry out the study were obtained from the Ethical Committee of the Faculty of Nursing, University of Alexandria.

2. Official letters were provided from the Faculty of Nursing administrative offices to the directors of the selected study setting" the Medical Outpatients' Clinic at SaidySalim General Hospital" to facilitate data collection, after explanation of the purpose of the study.

3. Tool development, validity: "Early stage liver cirrhotic patients dietary patterns and nutritional status structured interview schedule" was developed by the researcher based on a review of the recent relevant literature.

4. The developed tool was submitted to a panel of 5 experts in the nursing and medical fields to test its content validity and construct validity and necessary modifications were introduced.

5. Patients' consent was obtained and confidentiality and privacy were assured.

6. Tool reliability: the developed tool was tested by Cronbach's Alpha Coefficient statistical test which revealed that the tool reliability was $0,936^{(22)}$. 
7. A pilot study was conducted to ensure the clarity and applicability of the developed tool.

8. Data collection: data was collected from the identified subjects through interviewing about 30-45 minutes for each patient. Data were collected throughout the period of 4 months starting from midSeptember 2016, till the end of January 2017.

\section{Ethical considerations:}

Informed consents were obtained from the patients. The anonymity and confidentiality of patients' responses and privacy were assured.

\section{Statistical Analysis}

Data were analyzed using SPSS software package version 18.0 (SPSS, Chicago, IL, USA) (23). Pearson coefficient was used to analyze correlation between any two variables, $p$ value was assumed to be significant at 0.05 .

\section{Results}

Table (1) shows the frequency distribution of the studied patients in relation to their socio-demographic characteristics. The ages of more than two thirds of them $(73.6 \%)$ were $\geq 50$ years. While, more than half of the studied patients $(59.1 \%)$ were females. The majority of them $(84.3 \%)$ were married, while only $(2.4 \%)$ were single and none of them were divorced. Also, more than two thirds of studied patients $(63.4 \%)$ were living in rural area; the remaining $(36.6 \%)$ were urbans. Also, more than one-third of patients $(40.6 \%)$ were illiterate, while only $(5.1 \%)$ of them have had bachelor degree. More than half of patients $(64.2 \%)$ had no work (farmers), and $(15.4 \%)$ were employed. In addition, more than two thirds of patients $(74.0 \%)$ had low income. And, none of them were practicing any type of sports. Moreover, only (5.1\%) had meals outside home.
Table (2) presents the frequency distribution of the studied patients in relation to their clinical data. About half of patients (49. 2\%) had hepatitis $\mathrm{C}$ and fatty liver as a cause of the disease. In addition, only (12.2\%) of them had other causes as bilhariziasis and none of them were having alcohol as a cause of the disease. Also, more than half of the studied patients $(55.9 \%)$ used legalone as a current medication, while only ( $2.8 \%)$ of them were using Sofosbuvir and mpiviropack. The majority of patients $(90.2 \%)$ were using analgesics as an on the counter drugs, but none of them used vitamins.

Table (3) shows the correlations between overall dietary patterns and patients' nutritional status. No severe symptoms were experienced among the study participants, the majority of them $(78.6 \%)$ were having mild symptoms, and about $(41.3 \%)$ were having moderate symptoms. Also, no significant correlations were elicited between overall dietary patterns and patients nutritional status since p 0.141 .

Table (4) shows the correlations between overall dietary patterns and anthropometric, biochemical measurements. There were a significant correlations between each of (weight, BMI, TSF and fat percent) and overall dietary patterns since $p$ $(<0.001$ for each). On the other hand, there were no significant relationships between overall dietary patterns and the other anthropometric and biochemical measurements.

\section{Discussion}

In the current study the findings revealed that more than half of the studied patients were females and this could be due to postmenopausal reduction in female estrogen that protects women from liver damage, making them less susceptible to cirrhosis. This finding is in line with Roger (2015) who stated that women seem to be more prone to cirrhosis than men ${ }^{(24)}$.

Concerning the studied patients' marital status, the current study revealed 
that, the majority of them were married. This might be attributed to liability to increase viral infections transmission between married patients. This finding is in line with the findings of the study conducted by Ahmed (2015) who revealed that contacts who were married were more liable to be infected than the unmarried ${ }^{(25)}$.

Regarding residence, the current study found that more than two thirds of patients were living in rural areas; the remaining $(36.6 \%)$ were living in urban areas. This might be due to that the rural regions presented a suitable environment for developing schistosomal infection due to exposure to canal water that could be polluted by snails harboring the schistosomal parasites. This finding is in agreement with the results of Rao et al. $(2002)^{(26)}$.

Also, the present study results revealed that more than one-third of the studied patients were illiterate. Also most of them were coming from rural areas and the majority had low income. These finding are consistent with Sallam (2007) who reported that; more than half of the study patients were illiterate. But it contradicts the study carried out by Vanderplas et al. (2003) who revealed that the majority of his study patients had secondary education and this could be due to the different nature of the study population ${ }^{(27-29)}$.

Also, it was noticed that none of studied patients practiced any type of sports that may be due to advanced patients' age, as the majority of them were over 50. This finding is supported by a recent survey done by Hayashi et al. (2012) which reported that physical activity levels were lower in LC patients than in healthy controls $^{(30)}$.

As regards the etiology of liver disease, it was found that about half of the studied patients have had viral hepatitis $\mathrm{C}$. This might be attributed to lack of infection control awareness, dental procedures and tatoos. This finding is in line with Sharif et al. (2005) and Darwish et al. (2001) who stated that residents of Egypt's Nile River
Delta have among the world's the highest seroprevalence of hepatitis $\mathrm{C}$ virus (HCV) infection $^{(31,32)}$. Also fatty liver presented in the current study as a major cause of liver cirrhosis. This could be due to the participants' poor dietary intake related to increase in carbohydrate consumption which is a major source of fat composition and storage. This finding is in line with Guturu\& Duchani (2012), Ganetal (2011) and Hernaez (2012) as they stated that a combination of lifestyle and gender play a role in the pathogenesis of NAFLD ${ }^{(33-35)}$.

The study revealed that there were no significant correlations between the overall dietary patterns and patients' nutritional status. All of the studied patients were in the early stage of the disease in which there were no severe symptoms experienced by the study participants. This finding is in line with the study done by Teisanu (2012) found that unacceptable level of consumption of calories was predominant and increased with the progress of malnutrition that has a highly significant relationship with the progression of liver cirrhosis $^{(36)}$.

The findings of the present study revealed that there were no significant correlation between overall dietary patterns and the patients' nutritional status. This may be explained by that the patients were in the first stage of the disease in which there were no severe symptoms were found. This finding contradicts with Simon (2009) who stated that the patterns of dietary intake in patients seemed to be directly related to their nutritional status ${ }^{(37)}$.

A statistically significant relationship between patients' BMI and skin fold was found. These findings are similar to another study done by Maedica (2012) in that a positive correlation was found between these two parameters and the severity of cirrhosis $^{(38)}$.

According to the present study there were no statistically significant correlations between biochemical measurements and the overall dietary patterns. This may be due to the fact that the selected patients were in the 
first stage of the disease in which, liver functions were not severely deteriorated. These findings are supported by Taniguchi et al. (2013) who stated that in the early stages of liver cirrhosis, often there are no symptoms, with a reduced number of working liver cells ${ }^{(39)}$.

\section{Conclusion}

According to the findings of the present study, it can be concluded that, the majority of patients didn't have enough income and all of them weren't practicing any type of sports. In addition, there were significant relationships between each of (weight, BMI, skin fold thickness and fat percent) and the overall dietary patterns. On the other hand there were no significant correlations between other biochemical measurements. Also, studied patients suffered from mild and moderate symptoms of malnutrition and had no severe symptoms as they were in the early stages.

\section{Recommendations}

Based on the findings of the present study, the following recommendations are suggested:

1. Regular and complete nutritional assessment of liver cirrhosis patients should be carried out for early detection and treatment of malnutrition.

2. Nutritional health education program must be organized for early stages liver cirrhotic patients in order to limit the occurrence of further malnutrition and its complications.

Future researches are needed regarding:

1. Factors affecting nutritional status of liver cirrhosis patients and their effects on the patients outcomes.

2. The impact of nutritional programs on liver cirrhosis patients' outcomes. 
Table (1): Frequency distribution of the studied patients in relation to their sociodemographic data $(n=254)$

\begin{tabular}{|c|c|c|}
\hline Socio-demographic data items & No. & $\%$ \\
\hline $\begin{array}{l}\text { Age (years) } \\
30-<40 \\
40-<50 \\
\geq 50\end{array}$ & $\begin{array}{c}6 \\
61 \\
187\end{array}$ & $\begin{array}{c}2.4 \\
24.0 \\
73.6\end{array}$ \\
\hline $\begin{array}{l}\text { Min. - Max. } \\
\text { Mean } \pm \text { SD. }\end{array}$ & \multicolumn{2}{|c|}{$\begin{array}{c}32.0-60.0 \\
53.59 \pm 6.33\end{array}$} \\
\hline $\begin{array}{l}\text { Sex } \\
\text { Male } \\
\text { Female }\end{array}$ & $\begin{array}{l}104 \\
150\end{array}$ & $\begin{array}{l}40.9 \\
59.1\end{array}$ \\
\hline \begin{tabular}{|l|} 
Residence \\
Urbans \\
Rural \\
\end{tabular} & $\begin{array}{c}93 \\
161\end{array}$ & $\begin{array}{l}36.6 \\
63.4\end{array}$ \\
\hline $\begin{array}{l}\text { Marital status } \\
\text { Single } \\
\text { Married } \\
\text { Divorced } \\
\text { Widow } \\
\end{array}$ & $\begin{array}{c}6 \\
214 \\
0 \\
34\end{array}$ & $\begin{array}{c}2.4 \\
84.3 \\
0.0 \\
13.4\end{array}$ \\
\hline $\begin{array}{l}\text { Education } \\
\text { Illiterate } \\
\text { Read and write } \\
\text { Primary } \\
\text { Preparatory } \\
\text { Secondary } \\
\text { Bachelor degree }\end{array}$ & $\begin{array}{l}103 \\
14 \\
39 \\
25 \\
60 \\
13\end{array}$ & $\begin{array}{c}40.6 \\
5.5 \\
15.4 \\
9.8 \\
23.6 \\
5.1\end{array}$ \\
\hline $\begin{array}{l}\text { Occupation } \\
\text { An employee } \\
\text { Freelancer } \\
\text { Does not work }\end{array}$ & $\begin{array}{c}39 \\
52 \\
163\end{array}$ & $\begin{array}{l}15.4 \\
20.5 \\
64.2\end{array}$ \\
\hline $\begin{array}{l}\text { Income } \\
\text { Enough } \\
\text { Not enough } \\
\end{array}$ & $\begin{array}{c}66 \\
188 \\
\end{array}$ & $\begin{array}{l}26.0 \\
74.0 \\
\end{array}$ \\
\hline $\begin{array}{l}\text { Room number (except kitchen and bathroom } \\
\text { Min. - Max. } \\
\text { Mean } \pm \text { SD. }\end{array}$ & \multicolumn{2}{|c|}{$\begin{array}{c}2.0-4.0 \\
3.10 \pm 0.59\end{array}$} \\
\hline $\begin{array}{l}\text { Number of family members (living at home) } \\
\text { Min. - Max. } \\
\text { Mean } \pm \text { SD. }\end{array}$ & \multicolumn{2}{|c|}{$\begin{array}{c}2.0-10.0 \\
5.32 \pm 1.65\end{array}$} \\
\hline $\begin{array}{l}\text { Crowding index } \\
\text { Min. - Max. } \\
\text { Mean } \pm \text { SD. } \\
\end{array}$ & \multicolumn{2}{|c|}{$\begin{array}{l}0.67-2.67 \\
1.71 \pm 0.41\end{array}$} \\
\hline $\begin{array}{l}\text { Do you practice sport? } \\
\text { Yes } \\
\text { No }\end{array}$ & $\begin{array}{c}0 \\
254\end{array}$ & $\begin{array}{c}0.0 \\
100.0\end{array}$ \\
\hline $\begin{array}{l}\text { Are you having meals outside home? } \\
\text { No } \\
\text { Rarely } \\
\text { Sometimes } \\
\text { Always }\end{array}$ & $\begin{array}{l}116 \\
74 \\
51 \\
13\end{array}$ & $\begin{array}{c}45.7 \\
29.1 \\
20.1 \\
5.1\end{array}$ \\
\hline
\end{tabular}


Table (2): Frequency distribution of the studied patients in relation to their clinical data $(\mathbf{n}=\mathbf{2 5 4})$

\begin{tabular}{|c|c|c|}
\hline Clinical data items: & No. & $\%$ \\
\hline - Causes of the disease $(n=379)$ & & \\
\hline Alcohol & 0 & 0.0 \\
\hline Hepatitis B & 98 & 38.6 \\
\hline Hepatitis C & 125 & 49.2 \\
\hline Fatty liver & 125 & 49.2 \\
\hline Other (Bilharziasis) & 31 & 12.2 \\
\hline - $\quad$ Current medications $(n=321)$ & & \\
\hline |Legalone & 142 & 55.9 \\
\hline Lipitor & 14 & 5.5 \\
\hline Sofosbuvir & 7 & 2.8 \\
\hline Ribavirin & 39 & 15.4 \\
\hline Silimarin & 14 & 5.5 \\
\hline Declatazide & 14 & 5.5 \\
\hline Hepatovirin & 38 & 15.0 \\
\hline Mpiviropack & 7 & 2.8 \\
\hline Daclaferocrill & 14 & 5.5 \\
\hline Introvir & 32 & 12.6 \\
\hline - On the counter drugs $(n=321)$ & & \\
\hline Softeners & 134 & 52.8 \\
\hline Analgesics & 229 & 90.2 \\
\hline Herbs & 14 & 5.5 \\
\hline |Vitamins & 0 & 0.0 \\
\hline Others & 0 & 0.0 \\
\hline
\end{tabular}

- There are more than one answer.

Table (3): Correlations between overall dietary pattern and Patients nutritional status

\begin{tabular}{|c|c|c|c|c|c|c|}
\hline \multirow{4}{*}{ Patients health status items } & \multirow{2}{*}{\multicolumn{4}{|c|}{$\begin{array}{c}\text { Over all dietary patterns } \\
\text { Overall } \\
\end{array}$}} & \multirow{4}{*}{$\chi^{2}$} & \multirow{4}{*}{ p } \\
\hline & & & & & & \\
\hline & \multicolumn{2}{|c|}{$\begin{array}{c}\text { Mild } \\
<50 \\
(n=240)\end{array}$} & \multicolumn{2}{|c|}{$\begin{array}{c}\text { Moderate } \\
(\mathbf{5 0}-\mathbf{7 5 \%}) \\
(\mathrm{n}=\mathbf{1 4})\end{array}$} & & \\
\hline & No. & $\%$ & No. & $\%$ & & \\
\hline $\begin{array}{l}\text { Overall Symptoms } \\
\text { Mild symptoms }(<50 \%)\end{array}$ & 141 & 58.8 & 11 & 78.6 & & \\
\hline $\begin{array}{l}\text { Moderate } \\
(50-<75 \%)\end{array}$ & 99 & 41.3 & 3 & 21.4 & 2.163 & 0.141 \\
\hline Severe symptoms $(\geq 75 \%)$ & 0 & 0.0 & 0 & 0.0 & & \\
\hline
\end{tabular}

${ }^{2}, p: \chi^{2}$ and $p$ values for Chi square test

There are no severe symptoms found between the study participants 
Table (4): Correlations between overall dietary patterns and anthropometric, biochemical measurements

\begin{tabular}{|l|c|c|}
\hline \multirow{2}{*}{$\begin{array}{l}\text { Anthropometric and biochemical } \\
\text { measurements items }\end{array}$} & $\mathbf{r}$ & $\mathbf{p}$ \\
\hline Weight in kg & $0.727^{*}$ & $<0.001^{*}$ \\
\hline BMI & $0.330^{*}$ & $<0.001^{*}$ \\
\hline Skin fold thickness in cm & $0.269^{*}$ & $<0.001^{*}$ \\
\hline Mid arm circumference in cm & 0.074 & 0.238 \\
\hline The fat percent & 0.124 & 0.048 \\
\hline Percent water & -0.012 & 0.850 \\
\hline Muscle percent & 0.016 & 0.795 \\
\hline Bone percent & 0.018 & 0.772 \\
\hline Hemoglobin (mg/dl) & 0.015 & 0.809 \\
\hline White blood cells (x103) & -0.038 & 0.552 \\
\hline Platelet count (x103) & 0.007 & 0.914 \\
\hline Lymphocyte count (\%) & 0.060 & 0.343 \\
\hline Serum albumin (mg/dl) & 0.041 & 0.512 \\
\hline Prothrombin time (sec) & 0.027 & 0.781 \\
\hline Prothrombin activity (\%) & 0.671 \\
\hline
\end{tabular}

r: Pearson coefficient

*: Statistically significant at $p \leq 0.05$ 


\section{References}

1. American Family Physician. Nonalcoholic Fatty Liver Disease. World J Hepatol 2015 Dec 14; 7(11): 1550-9.

2. Muhlberger M., Schwarzer R., Lettmeier B., Sroczynski G., Zeuzem S., et al. HCV-related burden of disease in Europe: a systematic assessment of incidence, prevalence, morbidity and mortality. BMC Public Health 2009Dec 15; 7(1): 29-34.

3. WHO, Hepatitis C. Fact Sheet 2017 (164): 14.

4. Starr SP, Raines D. Cirrhosis: diagnosis, management, and prevention. Hepatology 2011Dec 15; 84(12):1353-9. Available at: http://www.ncbi.nlm.nih.gov/pubmed/222302 $\underline{69}$.

5. Knowlton F. Liver: Function, Failure \& Disease 2015. Available at: https://www.livescience.com.

6. Shea R, Dasarathy S, McCullough A Alcoholic liver disease. Hepatology. 2010; 51(1):307-328.

7. Gyamfi M, Wan Y. Pathogenesis of alcoholic liver disease: the role of nuclear receptors. Experimental Biology and Medicine 2010 Feb11; 235(5):547-560.

8. Norman K, Kirchner H, Lochs H, Pirlich M. Malnutrition affects quality of life in gastroenterology patients. World J Gastroenterol 2006Jun; 7(12):3380-5.

9. Krenitski J. Nutrition for Patients with Hepatic Failure. Practical Gastroenterology 2003 Jun; 8(6): 23-42.

10. Mueller C, Frazier T, Wheeler B, McClain C, Cave M. Liver Disease. In: ed. The A.S.P.E.N. nutrition support core curriculum $2^{\text {nd }} 2012$ Apr 7; 21(1) 454-471.

11. Zipprich A, Garcia-T, Rogowsky S, Fleig W, Seufferlein T, et al. Prognostic indicators of survival in patients with compensated and decompensated cirrhosis. Liver int 2012; 32(9): 1407-14.
12. Fung T. Chiuve S, Rimm E, Hu F, McCullough M, et al. Dietary indices both strongly predict risk of chronic disease. Nutrition 2012; 142 (6):1009-18.

13. Nicolaas E, Deut z, Jurgen M. Bauer, Rocco $\mathrm{B}$, et al. Protein intake and exercise for optimal muscle function with aging. Clinical Nutrition 2014 Dec; 33 (6): 929-936.

14. Kimbell B, Boyd K, Macgilchrist A, Murray A. Liver disease in the UK. Lancet 2016; 385(9967): 503. Available at: https://www.ncbi.nlm.nih.gov/pubmed/2570 5833.

15. Nettina, Sandra, M., Manual of Nursing Practice, 9th ed. Philadelphia: Lippincott Williams \& Wilkins; 2010. Chapter 20, Nutritional Problems;part two.

16. Ireton-Jones CS, Hasse JM. Comprehensive nutritional assessment. Hepatol Res 2006; 8:75-81.

17. Norman K.Prognostic impact of diseaserelated malnutrition. Clinical Nutrition 2007; 27:5-15.

18. Williams, Sue Rodwell. Nutrition and Diet Therapy. 8th edition. St. Louis. Mosby; 1997.

19. Schroder H. Covas MI. MarrugatJ.Vila J. Pena A. Alcantara M. Use of a three-day estimated food record, a 72-hour recall and a food-frequency questionnaire for dietary assessment in a Mediterranean Spanish population. Clinical Nutrition. 2001; 20 (5): 429-37.

20. Heather M. Patton, M.Nutritional Assessment of Patients with Chronic Liver Disease. Gastroenterol Hepatol (N Y) 2012 Oct; 8(10): 687-690.

21. Haslash. P. Vieira, Daurea A, De-Souza, Luiz C, Oliveira. Nutritional assessment in hepatic cirrhosis; clinical, anthropometric, biochemical and hematological parameters. NutrHosp 2013 Oct; 28(5):1615-1621

22. What does Cronbach's alpha mean? Institute for Digital Research and Education Available at: https://stats.idre.ucla.edu/spss/faq/whatdoes-cronbachs-alpha-mean/ 
23. Leslie E, Geoffrey J and James M (eds). Statistical analysis. In: Interpretation and uses of medical statistics $\left(4^{\text {th }} e d\right)$. Oxford Scientific Publications (pub) 1991; pp.4116.

24. Roger H. Liver cirrhosis. Lancet 2015; 4397 (42):838-51

25. Ahmed.R. Exploring Intrafamilial Transmission Risk Factors of Hepatitis C virus.Egyptian virus insight. Med J Cairo University 2015; 83 (2): 313-323.

26. Rao M, Naficy A, Darwish M, Darwish N, Schisterman, E,et al. Further evidence for association of hepatitis $\mathrm{C}$ infection with parenteral schistosomiasis treatment in Egypt. Hepatology 2002 Feb; Available at: http://www.PubMed.com

27. Sallam, I. The role of parenteral antischistosomal therapy in the spread of HCV in Egypt, 2007. Available at: http://www.PubMed.com

28. Migdad S, El-Sayed M, Mekkawy M, Abdelmalek M. Liver Cirrhosis: Impact of Nutritional Regimen on Patients Outcome. ISSN: 2320-1940 Volume 4, Issue 2 Ver. III (Mar.-Apr. 2015), PP 22-35.

29. Vanderplas, S., Iiansen, B., De Boer, J., Stijnen, T., Passo, J., De man, R., and Schalm, S., Generic and disease-specific health related quality of life in non-cirrhotic, cirrhotic, and transplanted liver pts, 2003. Available at: http://www.Medicine.come.

30. Hayashi F, Momoki C, Yuikawa M, Simotani Y, Kawamura E, Hagihara A, Fujii $\mathrm{H}$, Kobayashi S, Iwai S, Morikawa H, et al. Nutritional status in relation to lifestyle in patients with compensated viral cirrhosis. World J Gastroenterol. 2012; 18:5759-5770.

31. Sharif F., Mohebbi S., Tabtabaee H., Saberi M., Gholamzadeh S. Effect of psycho educational intervention on health related quality of life of patients with chronic liver disease referring to Shiraz university of medical science, 2005. Available at: http://www.PubMed.com.

32. Darwish M, Faris R, Darwish N, Shouman A, Gadallah M, et al. Hepatitis $\mathrm{c}$ and cirrhotic liver disease in the Nile delta of Egypt: a community-based study. Hepatology Research 2001 Apr; 64(3-4): 147-53.

33. Guturu P, Duchini A. Etiopathogenesis of Nonalcoholic Steatohepatitis: Role of Obesity. Insulin Resistance and Mechanisms of Hepatotoxicity. Int J Hepatology 2012; 212865.

34. Gan L, Chitturi S, Farrell G. Mechanisms and implications of age related changes in the liver. Nonalcoholic Fatty liver disease in the elderly. CurrGerontolGeriatr Res 2011; 831536.

35. Hernaez R. Genetic factors associated with the presence and progression of nonalcoholic fatty liver disease: a narrative review. Gastroenterol Hepatol 2012; 35(1):32-41.

36. Teisanu A, Andrie M, Arbanas T, Nicolaie $T$, Diculescu M. Nutritional status in cirrhotic patients, Maedica A Journal of Clinical Medicine 2012;7: 284-289.

37. Simon.M. Association between nutritional status and dietary intake in patients with cystic fibrosis.Nutrition 2009; 1806-3756.

38. Teiusanu A, Andrei M, Arbanas T, Nicolaie $\mathrm{T}$, Diculescu M. Nutritional status in cirrhotic patients. Maedica (Buchar) 2012; 7(4): 284-289.

39. Taniguchi E., Kawaguchi T., Otsuka M. Nutritional assessments for ordinary medical care in patients with chronic liver disease. Hepatol Res 2013; 43:192-99. 